\title{
Komparasi Akurasi Global Posistion System (GPS) Receiver U-blox Neo-6M dan U-blox Neo-M8N pada Navigasi Quadcopter
}

\author{
Firdaus $^{1 *}$, Ismail ${ }^{2}$ \\ ${ }^{12}$ Jurusan Teknik Elektro, Politeknik Negeri Padang \\ Jurusan Teknik Elektro Politeknik Negeri Padang, Jl. Limau Manih Padang, 25164, Indonesia \\ *Corresponding Author,e-mail: mrdauz@yahoo.com
}

\begin{abstract}
Abstrak- Pengembangan UAV quadcopter terjadi sangat pesat salah satu yang paling vital adalah sistim navigasinya baik hardware maupun software atau algoritma yang digunakan. Meningkatkan akurasi posisi quadcopter adalah salah satu topik popular dalam bidang UAV. Parameter posisi ini ditentukan umumnya oleh modul GPS. Modul GPS menghasilkan informasi posisi geografis dan kecepatan dengan tingkat presisi yang tinggi tapi modul ini rentan terhadap interferensi sehingga sinyal GPS sering hilang. Lebih dari itu frekuensi pengukuran GPS juga rendah sehingga tidak memenuhi syarat real-time. Dua varian GPS U-Blox, Neo-6M dan M8N menjadi pokok permasalahan dengan menguji keduanya manakah lebih tepat dan konsisten terhadap posisi geografis sebenarnya yang ditunjukkan Google map. Data yang diperoleh dari GPS receiver diurai dan dikonversikan ke koordinat longitude dan latitude oleh mikrokontroler IC ATmega328 kemudian dikombinasikan dengan data waktu real-time dari RTC DS1370 dan disimpan secara kontinyu ke dalam memori SD card berkapasitas 2 GB. Data koordinat geografis yang tersimpan nantinya akan diambil dan diubah ke format CSV agar dapat di-plot ke dalam peta. Pengujian dilakukan dimana GPS receiver Neo-6M dibawa melalui jalan Ombilin, Lapai 2, Limau Manih, Lapai 3 dan Kali Citarum dengan jarak tempuh 846,45 m, sedangkan GPS receiver Neo-M8N bergerak melewati jalan Ombilin, Lapai 2, Limau Bali, Lapai 3, dan Kali Citarum yang menempuh perjalalanan sejauh 756,27 m. Hasil komparasi akurasi antara modul GPS receiver Ublox Neo-6M dan GPS receiver Ublox Neo-M8N menghasilkan pergeseran sejauh rata-rata $1.75 \mathrm{~m}$ untuk Neo-6M dan 8,7 m untuk Neo-M8N sedangkan Neo-M8N lebih cepat mendapatkan data valid dari satelit. Namun kedua modul tersebut memiliki kondisi TIFF yang sama yaitu kurang lebih 2 menit.
\end{abstract}

Kata Kunci: GPS, navigasi, quadcopter, Ublox

\begin{abstract}
Quadcopter UAV development is happening very rapidly. One of the most important in the navigation system is the hardware and software or the used algorithm. Improving the accuracy of Quadcopter positioning is one of the most popular topics in the UAV field. This position parameter is determined by the GPS module. GPS modules produce position and speed information with a high degree of precision, but these modules are vulnerable to interference. Thus, GPS signals are often lost. Moreover, GPS measurements also cannot meet the real-time requirements. Both GPS U-Blox variants, Neo$6 M$, and M8N become the main problem by testing which are more precise and consistent with the actual geographical position indicated by Google map. Data obtained from GPS receivers are parsed and converted to longitude and latitude coordinates by the ATmega328 IC microcontroller then combine with real-time data from RTC DS1370 and stored continuously in a 2 GB SD card. The transferred geographic coordinate data would be retrieved and converted to CSV format so that it can be plotted into a map. The test was conducted where the Neo-6M GPS receiver was carried out
\end{abstract}

Keywords: GPS, navigation, quadcopter, Ublox

(C) 2020 Elektron Jurnal Ilmiah

\section{I.PENDAHULUAN}

Saat ini usaha pengembangan UAV (Unmanned Aerial Vehicles) quadcopter berlangsung begitu pesat salah satu yang paling vital adalah sistim navigasinya baik hardware maupun software atau algoritma yang digunakan [1][2][3]. Meningkatkan akurasi posisi quadcopter adalah salah satu topik popular dalam bidang UAV. Parameter posisi ini ditentukan umumnya oleh modul GPS seperti pada Gambar 1. Modul GPS menghasilkan informasi posisi geografis dan kecepatan dengan tingkat presisi yang tinggi tapi modul ini rentan terhadap interferensi sehingga sinyal GPS sering hilang. Lebih dari itu frekuensi pengukuran GPS juga rendah sehingga tidak memenuhi syarat real-time [4].Terdapat beberapa modul GPS receiver yang biasanya digunakan pada quadcopter komersial dengan harga terjangkau seperti merk U-Blox. Dua varian GPS tersebut adalah Neo-6M dan M8N. Permasalahan yang muncul adalah bagaimana keduanya akan diuji manakah lebih tepat dan konsisten terhadap posisi geografis sebenarnya yang ditunjukkan Google map. Multi GPS receiver sebelumnya digunakan untuk mendapatkan hasil yang lebih baik dari sensor IMU dalam menghasilkan orientasi 3D dari drone. Hasilnya adalah dalam 11 sesi penerbangan selama 5-7 menit diperoleh akurasi orientasi sebesar 2 derajat walaupun dalam keadaan cuaca mendung [5]. 




Gambar 1. Quadcopter dengan GPS receiver

Perbedaaan dengan beberapa penelitian sebelumnya [6] adalah memanfaatkan multi sensor untuk posisi Unmanned Aerial Vehicle (UAV), [7] [8] melakukan desain UAV, [5] menggunakan multi GPS untuk menentukan posisi UAV.

\section{METODE}

\section{A. Modul GPS receiver u-blox neo-6M}

Modul ini ditunjukkan pada Gambar 2 adalah penerima sinyal GPS stand-alone yang memiliki performa baik. Time to First Fix (TIFF) adalah salah satu parameter penting dimana didefenisikan sebagai kecepatan modul GPS untuk dapat mengakses data almanac dan emepheris dari satelit. TIFF, dan neo$6 \mathrm{M}$ ini memiliki TIFF paling lama 27 detik

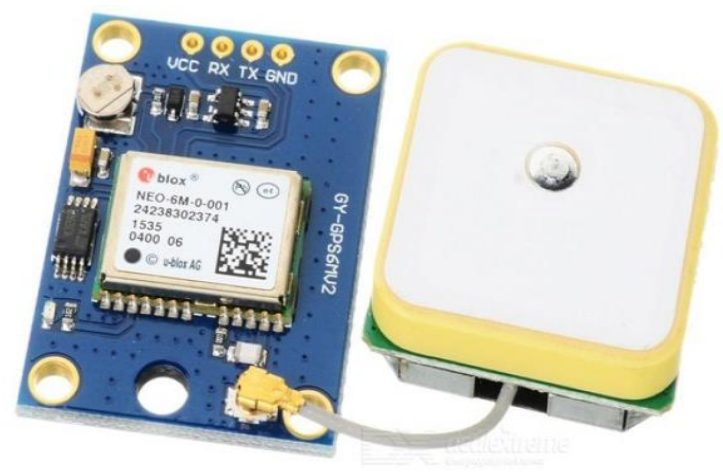

Gambar 2. Ublox neo-6M GPS receiver

Spesifikasi lain adalah, tegangan kerja maksimum 3,6 V, konsumsi arus maksimum $67 \mathrm{~mA}$, tipe receiver 50 chanel, update rate $5 \mathrm{~Hz}$, akurasi kecepatan $0,1 \mathrm{~m} / \mathrm{s}$, komunikasi interface UART [12].

\section{B. Modul GPS receiver u-blox neo-M8N}

Spesifikasi dari modul yang terlihat pada Gambar 3 adalah nilai TIFF maksimum 45 detik, tipe receiver 72 chanel, akurasi kecepatan $0,05 \mathrm{~m} / \mathrm{s}$, akurasi posisi horizontal $2,5 \mathrm{~m}$, update rate $10 \mathrm{~Hz}$, tegangan kerja $3,6 \mathrm{~V}$, arus konsumsi maksimum $67 \mathrm{~mA}$ dan komunikasi interface UART [13].

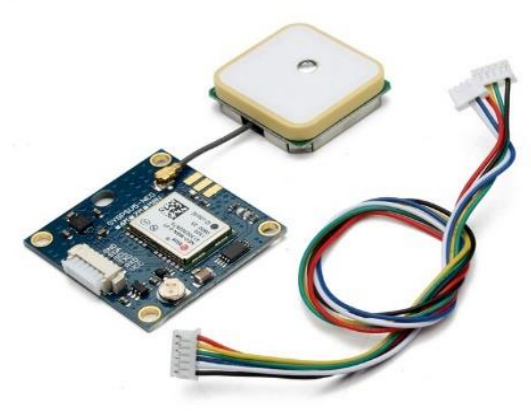

Gambar 3. Ublox neo-M8N GPS receiver

Modul GPS receiver Ublox-M6 dan Ublox-M8N menggunakan protokol RS232 untuk berkomunikasi dengan mikroprosesor oleh karena itu agar praktis maka diperlukan mikrokontroler seperti diilustrasikan pada Gambar 4 berikut,

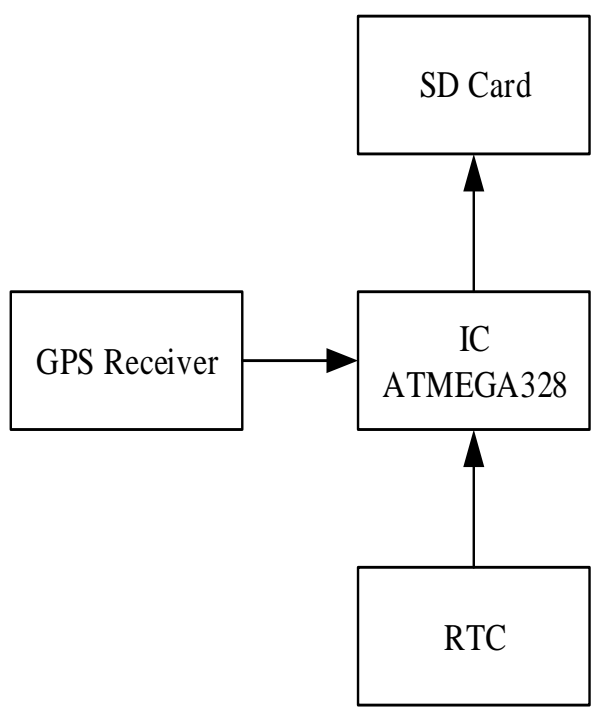

Gambar 4. Diagram blok hardware

Data yang diperoleh dari GPS receiver diurai dan dikonversikan ke koordinat longitude dan latitude oleh mikrokontroler IC ATmega328 kemudian dikombinasikan dengan data waktu real-time dari RTC (Real Time Clock) DS1370 dan disimpan secara kontinyu ke dalam memori SD card berkapasitas 2 GB. Data koordinat geografis yang tersimpan nantinya akan diambil dan diubah ke format CSV agar dapat di-plot ke dalam peta. Untuk mendapatkan nilai rerata pergeseran atau deviasi jarak koordinat yang terukur dengan koordinat sebenarnya, digunakan (1) dimana $\bar{d}$ adalah nilai rerata deviasi jarak, $d$ adalah sample perbedaan jarak antara koordinat saat pengukuran dengan koordinat 
sebenarnya, sedangkan $\mathrm{n}$ adalah banyaknya sample pengukuran.

$$
\bar{d}=\frac{\sum d}{n}
$$

Algoritma firmware pada mikrokontroler didesain berdasarkan flowchart yang terlihat pada Gambar 5,

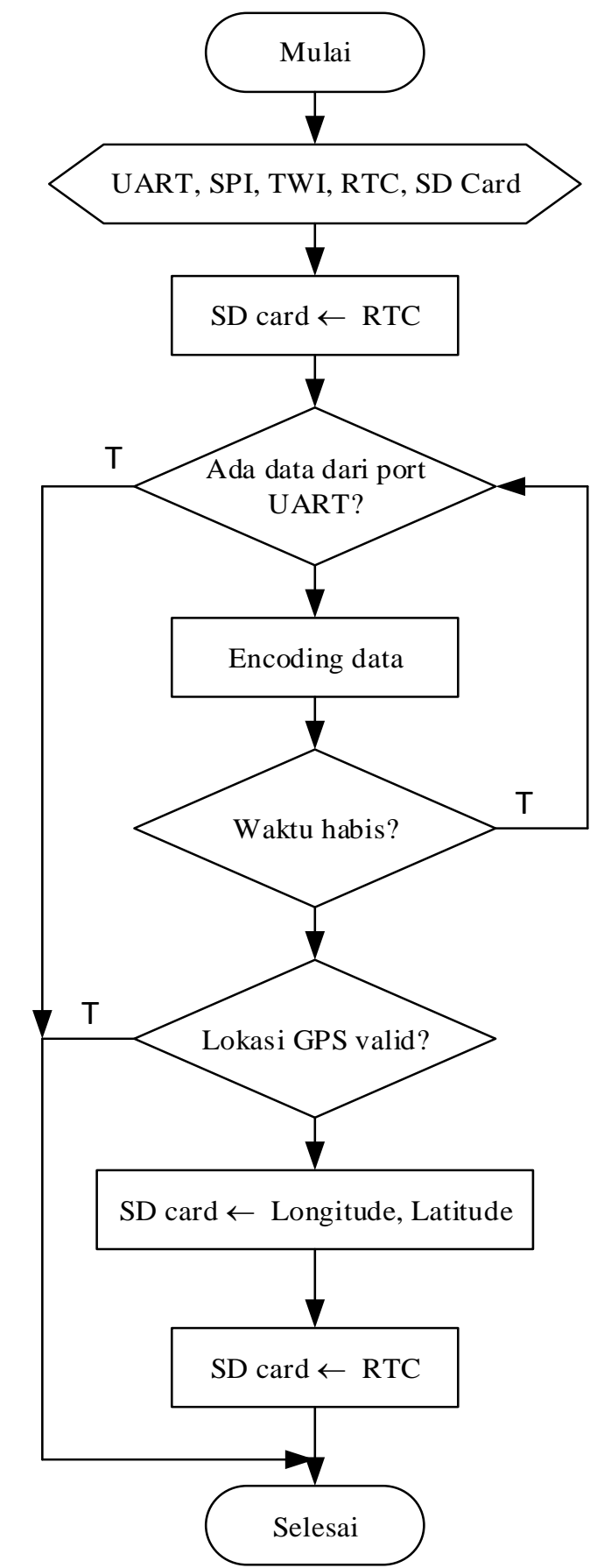

Gambar 5. Flowchart firmware

Inisialisasi dilakukan terlebih dahulu dengan mengaktifkankan port UART (Universal Asynchronous Receiver Transmitter), port SPI (Serial Peripheral Interface), port TWI (Two Wire Interface), modul RTC, dan modul memori SD card.
Saat GPS receiver diberikan tegangan pertama kali, data jam RTC disimpan di SD card untuk mendapatkan nilai TIFF. Satu persatu data GPS receiver yang sudah bearada dalam buffer UART diambil dan di-encoding menggunakan algoritma yang terdapat dalam library tinygps++.h hingga batas waktu 1 detik, kemudian validasi data diperiksa. Apabila status data sudah benar maka nilai longitude dan latitude beserta waktu saat itu disimpan di memori SD card.

Pengujian dilakukan dimana GPS receiver Neo6M dibawa melalui jalan Ombilin, Lapai 2, Limau Manih, Lapai 3 dan Kali Citarum dengan jarak tempuh 846,45 m, sedangkan GPS receiver NeoM8N bergerak melewati jalan Ombilin, Lapai 2, Limau Bali, Lapai 3, dan Kali Citarum yang menempuh perjalalanan sejauh $756,27 \mathrm{~m}$

\section{HASIL DAN PEMBAHASAN}

Waktu yang diperlukan GPS receiver dari pertama kali diberikan suplai tegangan hingga mencapai kondisi TIFF baik modul Neo-6M dan Neo-M8N sama-sama memliki waktu kurang lebih 2 menit

\section{A. Data tracking GPS receiver Neo-6M}

Gambar 6 menunjukkan garis berwarna biru adalah koordinat lintasan yang diinginkan sedangkan koordinat geografis hasil tracking Neo$6 \mathrm{M}$ berwarna merah. Dengan mengambil beberapa titik sampel koordinat antar keduanya ditemukan pergeseran titik koordinat yang diinginkan dengan titik koordinat yang dihasilkan Neo-6M rata-rata sejauh $1,75 \mathrm{~m}$. Awal bekerjanya modul terlihat garis merah sangat jauh dari garis biru hal ini karena modul masih mendapatkan data yang belum valid dari satelit dan pada jalan tersebut pula terdapat pepohonan rindang

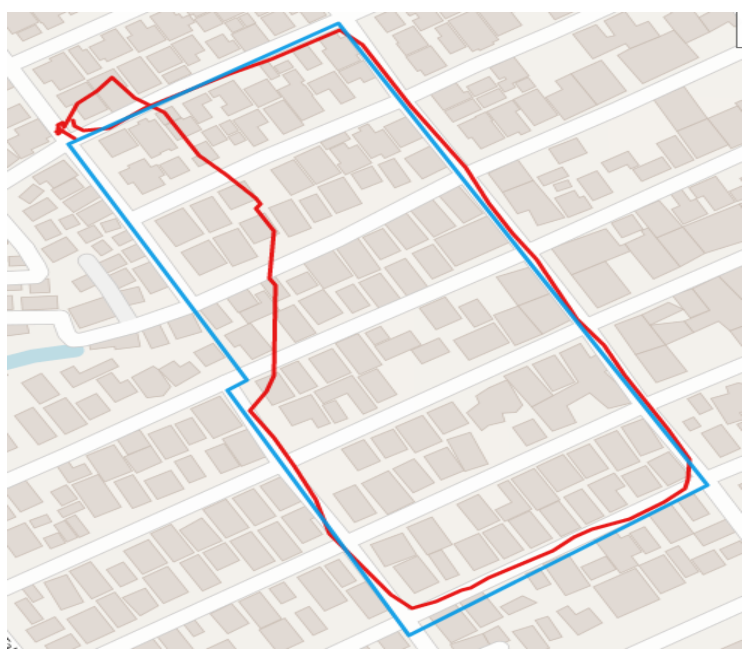

Gambar 6. Koordinat tracking GPS receiver Neo-6M 


\section{B. Data tracking GPS receiver Neo-M8N}

Gambar 7 menampilkan garis berwarna biru yang merupakan lintasan sebenarnya yang dilalui sedangkan garis berwarna merah adalah koordinat hasil tracking Neo-M8N. Pergeseran data modul terhadap lintasan yang sebenarnya cukup besar dengan jarak rata-rata $8,7 \mathrm{~m}$.

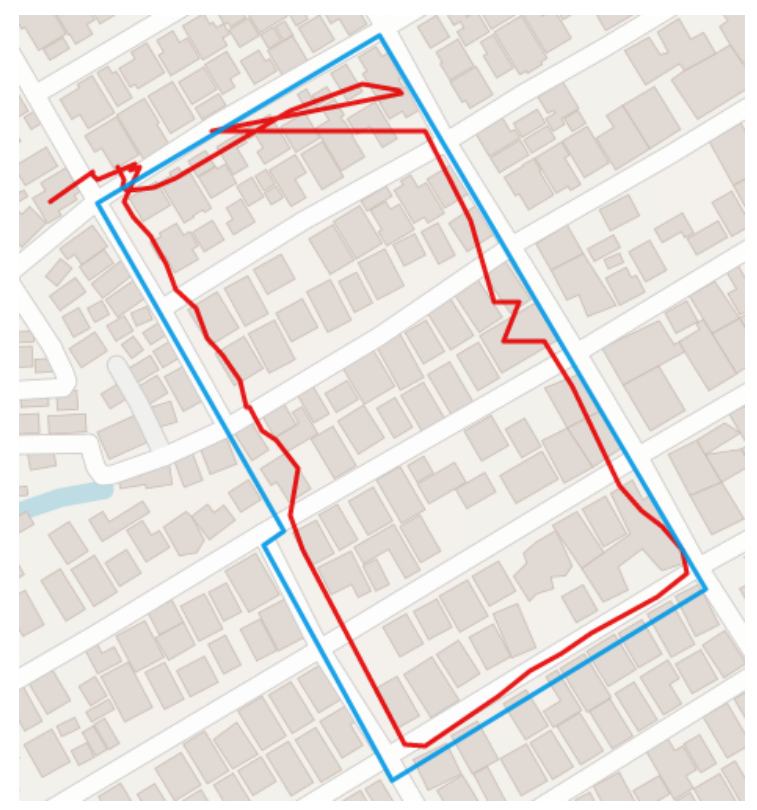

Gambar 7. Koordinat tracking GPS receiver Neo-M8N

Modul GPS receiver Neo-M8N lebih cepat mendapatkan data valid namun tidak terlalu tepat menunjukkan koordinat aktualnya dibandingkan GPS receiver Neo-6M.

\section{KESIMPULAN}

Komparasi akurasi antara modul GPS receiver Ublox Neo-6M dan GPS receiver Ublox Neo-M8N menghasilkan pergeseran sejauh ratarata $1.75 \mathrm{~m}$ untuk Neo-6M dan $8,7 \mathrm{~m}$ untuk NeoM8N sedangkan Neo-M8N lebih cepat mendapatkan data valid dari satelit. Namun kedua modul tersebut memiliki kondisi TIFF yang sama yaitu kurang lebih 2 menit.

\section{REFERENSI}

[1] Arya Adi Saputra, Andi Dharmawan. Rancang Bangun Quadcopter untuk Pemantauan Kadar Karbon Monoksida di Udara. IJEIS, Vol.3, No.1, April 2013, pp. 11 22

[2] Gembong Edhi Setyawan, Eko Setiawan, Wijaya Kurniawan.. Sistem Kendali Ketinggian Quadcopter Menggunakan PID. Jurnal Teknologi Informasi dan Ilmu Komputer (JTIIK) Vol. 2, No. 2, Oktober 2015, hlm. 125-131

[3] Futuhal Arifin, Ricky Arifandi Daniel, Didit Widiyanto. Autonomous Detection And Tracking Of An Object Autonomously Using Ar.Drone Quadcopter. Jurnal Ilmu Komputer dan Informasi (Journal of Computer Science and Information). 7/1 (2014), 11-17

[4] J. Wang, M. Garratt, A. Lambert, J. Wang, S. Han, and D.
Sinclair, Integration of GPS/INS/vision sensors to navigate unmanned aerial vehicles, vol. 37. 2008.

[5] M. Gowda, J. Manweiler, A. Dhekne, R. R. Choudhury, and J. D. Weisz, "Tracking drone orientation with multiple GPS receivers," Proc. Annu. Int. Conf. Mob. Comput. Networking, MOBICOM, vol. 0, no. 1, pp. 280-293, 2016, doi: $10.1145 / 2973750.2973768$.

[6] W. Li and Z. Fu, "Unmanned aerial vehicle positioning based on multi-sensor information fusion," Geo-Spatial Inf. Sci., vol. 21, no. 4, pp. 302-310, 2018, doi: 10.1080/10095020.2018.1465209.

[7] R. K. S. Sravan kumar N, "Design And Control Implementation Of Quadcopter," Int. Adv. Res. J. Sci. Eng. Technol., vol. 3, no. 2, p. 4, 2016.

[8] A. Singh Rajpoot, N. Gadani, and S. Kalathia, "Development of Arduino Based Quadcopter," Int. Adv. Res. J. Sci. Eng. Technol., vol. 3, no. 6, pp. 252-259, 2016, doi: 10.17148/IARJSET.2016.3649.

[9] A. Koubaa and B. Qureshi, "DroneTrack: Cloud-Based RealTime Object Tracking Using Unmanned Aerial Vehicles over the Internet," IEEE Access, vol. 6, pp. 13810-13824, 2018, doi: 10.1109/ACCESS.2018.2811762.

[10] J. Kwak and Y. Sung, "Autonomous UAV Flight Control for GPS-Based Navigation," IEEE Access, vol. 6, pp. 3794737955, 2018, doi: 10.1109/ACCESS.2018.2854712.

[11] T. C. Mallick, M. A. I. Bhuyan, and M. S. Munna, "Design \& Implementation of an UAV (Drone) with Flight Data Record," 2016 Int. Conf. Innov. Sci. Eng. Technol. ICISET 2016, 2017, doi: 10.1109/ICISET.2016.7856519.

[12] U-blox, "NEO-6 GPS Modules Data Sheet," $W w w . U$ Blox.Com, p. 25, 2017.

[13] D. Sheet, "NEO-M8." 